\title{
DA VOZ DO POEMA À VOZ DA CANÇÃO: A MUSICALIZAÇÃO DE POEMAS DE HELENA KOLODY - RELAÇÕES INTERARTÍSTICAS
}

\section{FROM THE POETIC VOICE IN POETRY TO THE POETIC VOICE IN SONGS: INTERARTISTIC RELATIONS IN THE MUSICALIZATION OF HELENA KOLODY'S WORKS}

\author{
Cristian Javier Lopez ${ }^{11}$
}

\begin{abstract}
RESUMO: A poeta paranaense Helena Kolody (1912-2004) desenvolve uma produção lírica que dialoga com as temáticas próprias dos poetas da sua geração e na qual se destaca a figura do imigrante ucraniano no Brasil, a efemeridade do tempo, o sentimento de pátria, entre outras. Além das temáticas mencionadas, sua obra apresenta um cuidado especial com o nível estrutural, imagético e fônico do poema, nos quais é notável o aspecto inerente à musicalidade, na qual encontramos o desenvolvimento de um trabalho pessoal com os elementos naturais da linguagem musical numa tentativa de conjugá-los à própria expressão da palavra. Essa musicalidade na sua obra levou o músico acadêmico Henrique de Curitiba (1934-2008) a compor canções dentro do âmbito do canto lírico, baseadas nos poemas de Kolody. Tais criações apresentam-se como uma ressignificação do poema, considerando esse como produto artístico que, ao se transformar em canções, reveste de uma nova roupagem a poesia. Isso possibilita a abrangência da obra kolodyana a outras esferas das artes. O campo da poesia lírica no Brasil sempre teve uma intensa atividade na qual se destacou a presença masculina e das poetas que fazem parte do cânone literário brasileiro, prestigiadas em menor medida, são destacadas somente aquelas que pertenceram aos grandes centros. Este trabalho busca trazer a obra poética da escritora do Paraná, ancorado nos pressupostos teóricos de Blacking (2015), Souriau (1986), Tatit (2007), entre outros, com o intuito de aportar estudos que valorizem as produções que ficaram esquecidas ou relegadas a espaços específicos, regionais ou estaduais, possibilitando expor a relevância que sua obra merece.
\end{abstract}

PALAVRAS-CHAVE: Helena Kolody. Música e Literatura. Literatura Comparada. Vozes femininas.

ABSTRACT: Helena Kolody (1912-2004) is a poet from Paraná. Her lyrical works dialogue with subject matters known to her generation. Among other motifs in her works we can highlight the figure of the Ukrainian immigrants in Brazil, the ephemerality of time and the feeling of attachment to one's native land. Her works reveal special attention towards the structural, imagetic and the phonic level of poetry and inherence to musicality. This last aspect is used in order to conjugate her word expression to the natural elements of the musical language. Such musicality inherent to her works led Henrique de Curitiba (1934-2008) to compose songs, within the Lyrical singing sphere, based on poems by Kolody. Those creations give new meanings to her poetry. Thus, this occurs because poems are considered artistic products. When those pieces of art are transformed into songs, they acquire a new gown. Thereby this process allows the insertion of Kolody's works into other artistic spheres. The lyric poetry's sphere in Brazil has always had an intense activity, where masculine representatives have the spotlight. Among the female poets, the ones who take part of the Brazilian poetry canon, which are renowned to a lesser extent, only those who belong to the metropolis are highlighted. This paper aims to discuss the poetry of Kolody supported by Blacking (2015), Souriau (1986), Tatit (2007), and others. Hence, the past forgotten productions, or the works that have been pushed aside to the regional or statewide area, without getting the merited recognition, will be treasured in the present paper.

KEYWORDS: Helena Kolody. Music and Literature. Comparative Literature. Female Voices.

\section{Introdução}

A poética de Helena Kolody se apresenta no panorama da literatura brasileira com o cultivo das formas fixas, a forma nipônica haicai e o verso livre. Dentro das temáticas

\footnotetext{
${ }^{11}$ Doutorando do programa de Pós-graduação da Universidade de Vigo-Espanha e Mestre em Teatro e Artes Cênicas, área Estudos Literários, pela Universidade de Vigo-Espanha. Integrante do grupo de pesquisa "Ressignificações do passado na América Latina: processos de leitura, escrita e tradução de gêneros híbridos de história e ficção - vias para a descolonização", coordenado pelo Prof. Dr. Gilmei Francisco Fleck. E-mail: cj_lopez2@hotmail.com
} 
desenvolvidas pela poeta encontramos aspectos relacionados à imagem do imigrante, à crítica social, à efemeridade do tempo, à musicalidade, entre outras.

No tocante à última temática mencionada, a musicalidade, abordamos, neste texto, a obra de Helena Kolody desde a perspectiva da comparação literário-musical, cuja materialização está nas composições do músico erudito brasileiro Henrique de Curitiba, quem, no ano de 1999, compôs a obra para canto e piano "Seis Poemas de Helena Kolody" ". Dita obra foi apresentada no XIX Festival de Música de Londrina, como homenagem à poeta brasileira. Em sua composição musical Henrique de Curitiba selecionou os poemas "Voz da Noite", "Viagem Infinita", "Cantar", "Cantiga de Roda", "Âmago" e "Nunca e Sempre", pertencentes às obras Ontem Agora (1991), Poesia Minima (1986), Sempre Palavra (1985) e Vida Breve (1964), respectivamente. Desse modo, a seguir, discorremos sobre tais poemas e sua transposição à arte musical.

\section{A musicalidade da obra de Helena Kolody concretizada em seis poemas: cantos à vida}

A confluência entre as artes se expressa de maneira clara na obra de Helena Kolody e Henrique de Curitiba, e o produto híbrido resultante dessa ação explora os aspectos fônicos e estruturais da língua - inerentes à poesia de Kolody - em consonância com a arte musical aplicada na obra por Henrique de Curitiba. Tal fato permitiu uma conjunção entre língua e música que ficou marcada nas canções do músico brasileiro que explorou tais aspectos da obra kolodyana em convergência com a arte do canto lírico.

Expomos, a seguir, os poemas escolhidos pelo compositor ${ }^{13}$ para levar a poesia de Kolody a outro público, em outra época, sob uma nova roupagem: a música.

\section{Cantar}

Quem vai cantando

não vai sozinho.

Dançam em seu caminho

o sonho e a canção. ${ }^{14}$ (KOLODY, 2011, p. 40).

Nessa composição, apresenta-se uma linguagem coloquial, típica das cantigas, o que torna o poema fácil de ser lembrado. A construção é a de uma quadra, dividida em duas partes de dois versos cada uma delas. Os dois primeiros versos são tetrassílabos ou quebrados de redondilha maior, de um ritmo simples, oportuno para a construção da canção.

O segundo grupo, versos terceiro e quarto, são hexassílabos, ou heroicos quebrados. No corpo do poema, verificamos um efeito de aliteração e assonância com sons nasais, outorgados pelas consoantes "m" e "n" e pelas vogais nasalizadas "ã", "i”" e "õ": "Quem vai cantando/ não vai sozinho./ Dançam em seu caminho/ o sonho e a canção."

\footnotetext{
${ }^{12}$ A obra utilizada para este artigo é a versão publicada pela Universidade Federal do Paraná no ano de 2003.

${ }^{13}$ Conforme registra Antonio Donizeti da Cruz (2010, p. 44): "vários poemas da autora foram musicados. O primeiro foi 'Prece', em 1950, da obra Paisagem interior, pela cantora carioca Babi de Oliveira, que o musicou e cantou em seus recitais. Por volta de vinte anos mais tarde, o maestro Pedro de Castro musicou-o também. No dia 29 de outubro de 1965, num concerto de composições de Helza Camêu, apresentado pelo 'Círculo de Artes Vera Janacópulus', no auditório do Conservatório brasileiro de Música, no Rio de Janeiro, foram interpretados os poemas de Helena: 'Prenúncio de outono' e 'A sombra no rio', cantados por Hermelindo Castello Branco, e 'Música eterna', cantado por Maria Sylvia Pinto."

${ }^{14}$ A obra utilizada para as citações da produção lírica de Helena Kolody corresponde à edição comemorativa que reúne a obra completa da poeta, organizada por Adélia Maria Woellner, no ano de 2011.
} 
A construção, em ambos os grupos de dois versos, é realizada por enjambement, o que outorga um efeito de sonoridade peculiar de pergunta e resposta.

Abaixo está transcrito o seguinte poema que compõe a lista dos eleitos por Henrique de Curitiba para transformar a poesia lírica de Kolody (2011, p. 143) em música erudita:

\section{Cantiga de Roda}

Ao som de ingênua cantiga

Gira ligeira, uma roda.

Bailam cabelos de linho, Brilha a cantiga nos olhos, Saltam, leves, os pezinhos.

Os grandes cedros antigos, Também se põem a bailar: Cantam os ramos no ar, dançam as sombras no chão.

Esse poema está construído em versos heptassílabos, ou redondilha maior, cuja estrutura traz à lembrança as cantigas medievais e canções populares em língua portuguesa.

Estruturalmente se conforma com três estrofes em ordem crescente. A primeira é um dístico, a segunda um terceto e a última uma quadra.

Essa estrutura crescente tem significância pelo fato de que o eu lírico vai pintando um quadro que, no final, elucida uma cena bucólica. No dístico, o eu-lírico apresenta o tema mencionado no título: uma cantiga. A poeta, para criar o efeito circular próprio das cantigas de roda, valeu-se de efeitos fônicos, como a utilização de vogais abertas, tais como o "A" e o "O", a consoante fricativa "G" e a consoante palatal "R": "Ao som de ingênua cantiga/ Gira ligeira, uma roda." Destacamos, nesse verso, a presença da palavra "ingênua", que ganha importância na próxima estrofe.

No terceto, o eu-lírico amplia a cena, mostrando indícios de quem está cantando a ingênua cantiga: crianças. A estrofe apresenta movimento, materializado pela utilização de verbos no presente do indicativo: "bailam, brilha e saltam".

A presença de elementos como "cabelos de linho" oferecem a possibilidade de pensar que se tratam de crianças loiras que cantam a cantiga de roda. Este ponto é importante, pois, na sua produção, a autora tentou recriar uma imagem de sua infância, cuja essência ainda é cultivada pelos imigrantes ucranianos. Assim, podemos imaginar que é da sua memória que se forma a cena concretizada na canção-poema.

No quarteto, o quadro se abre, outorgando uma visão de conjunto na qual aparece um elemento antigo que se relaciona com a ideia da cantiga medieval: cedros antigos. Existe um efeito de sonoridade criado pela autora que imita o vento na construção da imagem de movimentos das árvores que "também se põem a bailar": a imagem recriada de movimentos, que nos traz a ideia de sonoridade e vento, está materializada em "Cantam os ramos no ar,/ dançam as sombras no chão".

\section{Do poema à canção: transposição da letra para a partitura}

Entre os poemas eleitos pelo compositor Henrique de Curitiba está, ainda, "Voz da noite" (KOLODY, 2011, p. 27), que transcrevemos na sequência: 


\section{Voz da Noite}

O sol se apaga.

De mansinho

a sombra cresce.

A voz da noite

diz, baixinho:

esquece... esquece...

Essa composição apresenta-se com uma estrutura simétrica, composta de dois tercetos, cuja divisão silábica é: 4-3-4. Nela existe rima entre o segundo e o quinto verso "inho" e o terceiro e o sexto verso "esce" e "ece".

O elemento fônico se faz presente desde o título. Ele nos convida a "ouvir" a voz da noite. Para tal motivo podemos pensar na recursividade da letra "O", utilizada para exemplificar o elemento luminoso "Sol", que se desvanece no final da tarde. Esse efeito de apagar-se está estritamente conectado à vogal "A", central baixa, que finaliza o primeiro verso, outorgando-lhe essa sensação de término, que é reforçado pelo sinal de pontuação.

No segundo verso, a ideia exposta é a do crescimento, que se efetua devagar. Essa sensação é perceptível pelo uso de vogais mais fechadas como o "I". Destacamos que a pronúncia, no português brasileiro, do conjunto formado pela consoante "d" com a vogal "E" exerce um efeito de elevação da vogal "E" para a vogal "I". Portanto, lê-se "di mansinho". Já no terceiro verso aparece o signo "noite", mediante o uso da vogal "O", cujo verso termina com a vogal "E".

$\mathrm{Na}$ segunda estrofe, a "noite" aparece em destaque. Isso se aprecia na utilização da vogal "O" aberta, ocupando o acento tônico, no mesmo lugar que ocupava a palavra "sol" no primeiro verso. Tal aspecto é reforçado pela vogal "O", da palavra "noite", no segundo acento do verso. Vemos, em seguida, que a poeta utiliza o mesmo recurso que usou no terceto anterior, pois, no verso trissilábico, aparece a utilização do som fechado da vogal "I".

O poema termina com um verso, cujas vogais vão marcando uma continuidade até decrescer e que, no português do Brasil, praticamente se converte em "I". De acordo com a estudiosa Tatiana Slama-Cazacu, vemos que "a veces, el final de la palabra - considerado "más débil" porque la voz se debilita al emitirlo - se revela como la parte más importante de la palabra [...]" (SLAMA-CAZACU, 1970, p. 250) no fazer poético.

Para demonstrar, de forma comparativa e esquemática, como se estabelece a relação do poema com a sua musicalização, propomos, a seguir, a transcrição dos poemas "Voz da noite" e "Âmago", dois dos poemas de Kolody que foram musicalizados por Henrique de Curitiba, para uma forma mais próxima da linguagem musical. Para isso, utilizamos um esquema que representa a extensão melódica. Este esquema adquire a forma de uma partitura simplificada, seguindo o modelo feito anteriormente por Tatit (2007), para verificar a extensão melódica de certas canções.

Nessa proposição esquemática visual da musicalidade, buscamos representar como a linha melódica tem correspondência com a "massa sonora"15 do verso. Usamos, para isso, um quadro de representação da extensão melódica, segundo o modelo de Tatit (2007), que abrange da nota mais grave àquela mais aguda na composição musical.

Essa representação será feita, por nós, seguindo os versos dos poemas que foram musicalizados. Desse modo, é-nos possível comparar a representação da extensão melódica dos versos de Kolody com a partitura de Henrique de Curitiba (2003) que os musicalizou.

\footnotetext{
${ }^{15}$ VILARIÑO, I. La masa sonora del poema. Montevideo: Biblioteca Nacional, 2016.
} 
Assim, semelhanças e diferenças entre as duas linguagens ficam visualmente esquematizadas e nos permitem refletir sobre como ocorre a relação de confluência entre a literatura e a música, ao menos, no caso específico do corpus aqui analisado.

O número de linhas que cada quadro de representação da extensão melódica contém equivale à extensão desse aspecto composicional inerente a cada composição musical. Portanto, elas podem variar de acordo com a canção analisada. Vejamos como isso se concretiza nos três primeiros versos do poema "Voz da noite" (KOLODY, 2011, p. 27):

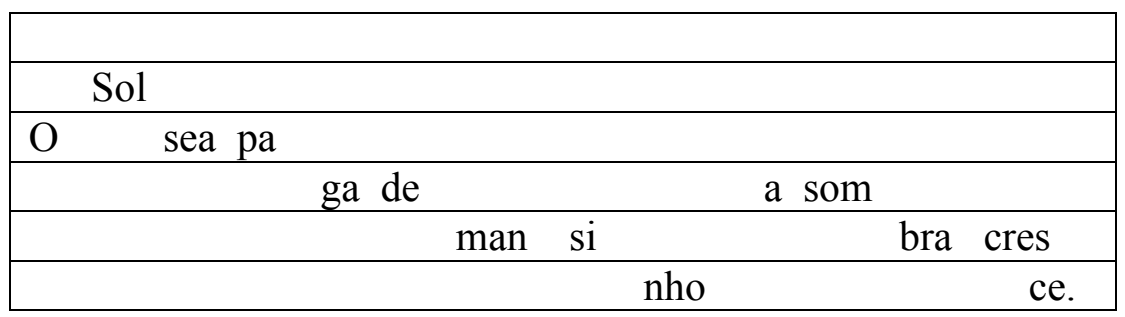

Esquema de extensão melódica - Fonte: Autor, baseado no esquema de Tatit (2007).

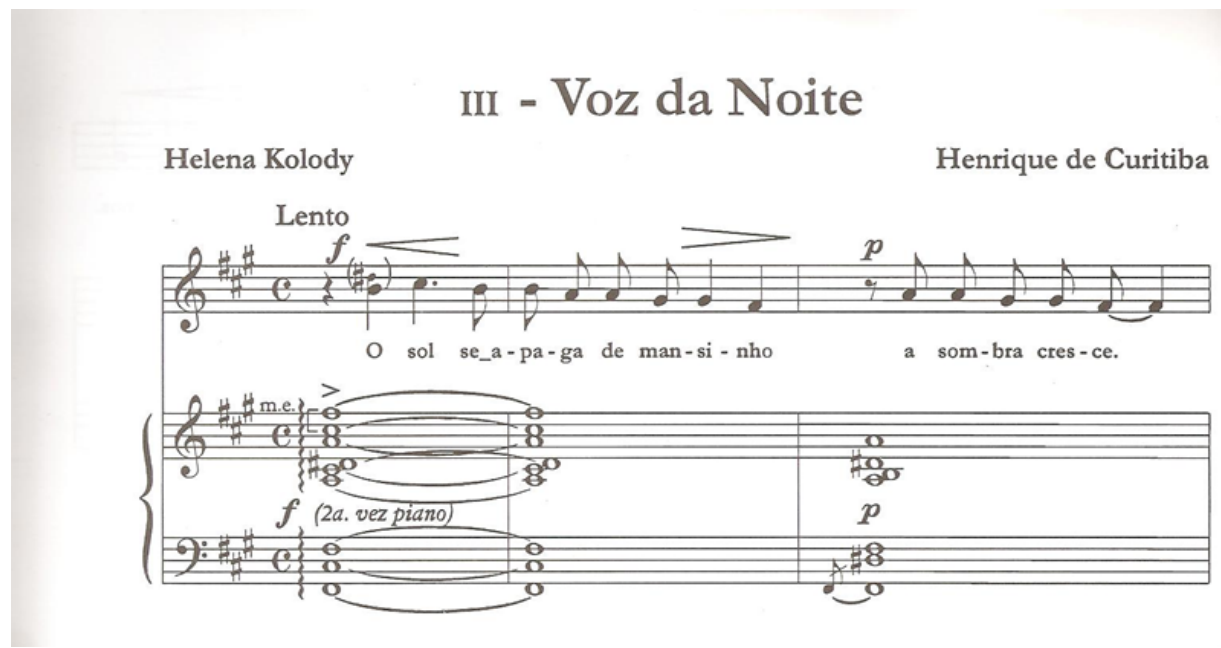

Partitura 3: "Voz da noite"

Fonte: Henrique de Curitiba (2003) - Seis Poemas de Helena Kolody: canções para soprano e piano.

Nesse caso, a representação esquemática abrange uma extensão de seis notas - cada uma delas corresponde a uma linha do esquema da extensão melódica. Essas vão de "fá" a "ré sustenido", compostas na clave de fá menor, como está posto na partitura. No esquema proposto, é perceptível o percurso da melodia que tem um tom decrescente, conforme a composição poética sugere.

Como ponto a destacar na comparação entre o poema e a partitura que the deu musicalidade, está a questão de que, na letra proposta à composição musical, para a primeira estrofe, existe uma variação que se realiza pela falta do signo de pontuação (ponto final, após o primeiro verso) presente no poema: "O sol se apaga. $\backslash$ De mansinho $\backslash$ a sombra cresce" que, na partitura, desaparece sem que seja marcado por qualquer signo musical, como silêncio ou cesura. Tal aspecto sugere uma nova leitura para a sequência lógica das ações presentes no enunciado do poema no qual se lê: "O sol se apaga. De mansinho a sombra cresce" para "O sol se apaga de mansinho [silêncio musical] a sombra cresce". Essa nova sequência leva o leitor-ouvinte, suposto conhecedor da obra de Kolody, a notar a "leitura" musical diferenciada que a mensagem adquire nessa outra linguagem. Nesse sentido, confirmamos, nesta análise, um fato mencionado por Tatit (2007): 
A canção promove a remotivação constante dos componentes próprios do discurso oral - cadeia linguística e perfil entoativo - gerando entre eles outras formas de compromisso que se pautam, em geral, pela estabilidade e conseqüente fortalecimento do plano da expressão. Durante essa operação, a relação sujeito/objeto vai sendo reproduzida na letra, na melodia e demais recursos musicais, ora dentro de uma dimensão extensa, ora através do contato de elementos vizinhos, mas sempre em função do estreitamento dos laços entre expressão e conteúdo. (TATIT, 2007, p. 45).

Embora exista essa diferença, o esquema melódico apresenta semelhança entre ambas as composições artísticas. Essas se concretizam, por exemplo, na utilização de notas agudas na partitura naquelas vogais tônicas, do português do Brasil, presentes, por exemplo, nos signos "sol" - vogal posterior semiaberta baixa /ó/ - e "som" - vogal posterior semifechada média /o/ - usados nos primeiros versos do poema.

Já a segunda parte da canção, “A voz da noite/ diz, baixinho:/ esquece... esquece”, que correspondente à segunda estrofe do poema, revela outras particularidades, como é possível observar na esquematização feita abaixo:

\begin{tabular}{|c|c|c|}
\hline \multicolumn{3}{|c|}{ Voz } \\
\hline A & da noi & \\
\hline & te diz & diz \\
\hline & bai xi & bai xi \\
\hline & nho & nho \\
\hline
\end{tabular}

Esquema de extensão melódica - Fonte: Autor, baseado no esquema de Tatit (2007).

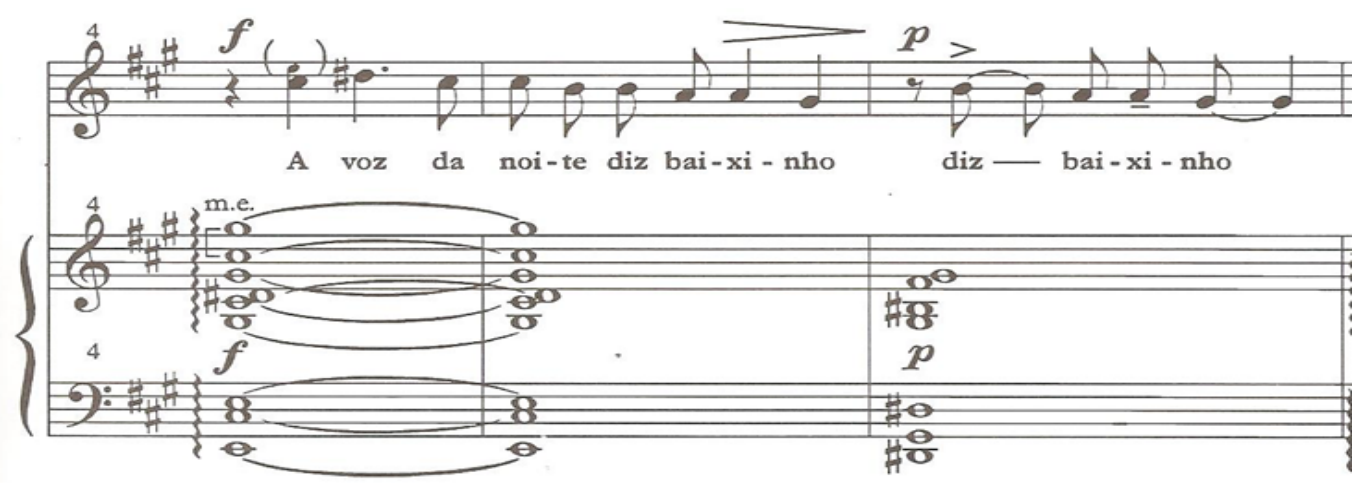

Partitura 3: "Voz da noite"

Fonte: Henrique de Curitiba (2003) - Seis Poemas de Helena Kolody: canções para soprano e piano.

Nesse segmento, vemos que o signo "Voz" ocupa a nota mais aguda da extensão. Isso corrobora a importância poética dessa palavra que, naturalmente, tem destaque fônico, pois insere uma vogal "o" aberta na massa sonora do poema, a qual o compositor soube destacar na extensão musical. Tal articulação entre a letra do poema e a musicalização que dele se fez reforça a convergência literário-musical no que tange à criação do novo produto artístico que desta junção nasce. Além disso, o destaque desta palavra com a nota mais aguda da composição revela que 
[...] o processo de estabilização melódica de uma canção prevê necessariamente a imbricação dos ataques rítmicos (representados foneticamente pelas consoantes e acentos vocálicos) com as durações de sonoridade propriamente dita (instaladas foneticamente nas vogais), dando origem ao que chamamos de perfil rítmico-melódico. (TATIT, 2007, p. 45).

Existe, nessa parte, uma variação entre a composição musical e a obra literária. Essa diz respeito à repetição do verso quinto "diz, baixinho" que, na composição musical, é repetido sem vírgula e com as mesmas notas "diz baixinho [silencio musical] diz baixinho". Esta repetição obedece a uma necessidade à construção de harmonia no sentido de equilíbrio, pois já se vai chegando ao final da música, que termina com duas palavras. A construção musical realizada propõe uma prévia do que será o seu final: uma repetição em forma de eco. Esse é, também, um modo especial da linguagem musical "interpretar" os possíveis sentidos do enunciado poético, da mesma forma como o leitor tem a liberdade de fazê-lo ao utilizar-se de seu universo de conhecimentos prévios para atribuir sentido à poesia lida.

Vejamos, pois, como isso se materializa na composição musical lírica do último verso do poema, esquematizado abaixo:

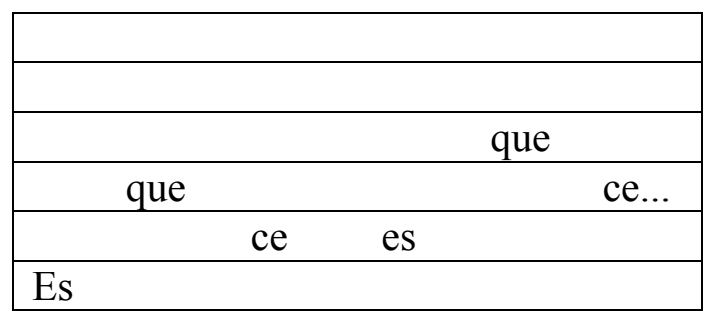

\begin{tabular}{|ll|}
\hline \multicolumn{2}{c|}{} \\
\hline \multicolumn{2}{c|}{ es } \\
\hline que que \\
\hline ce... \\
\hline Es \\
\hline
\end{tabular}

Esquema de extensão melódica - Fonte: Autor, baseado no esquema de Tatit (2007).
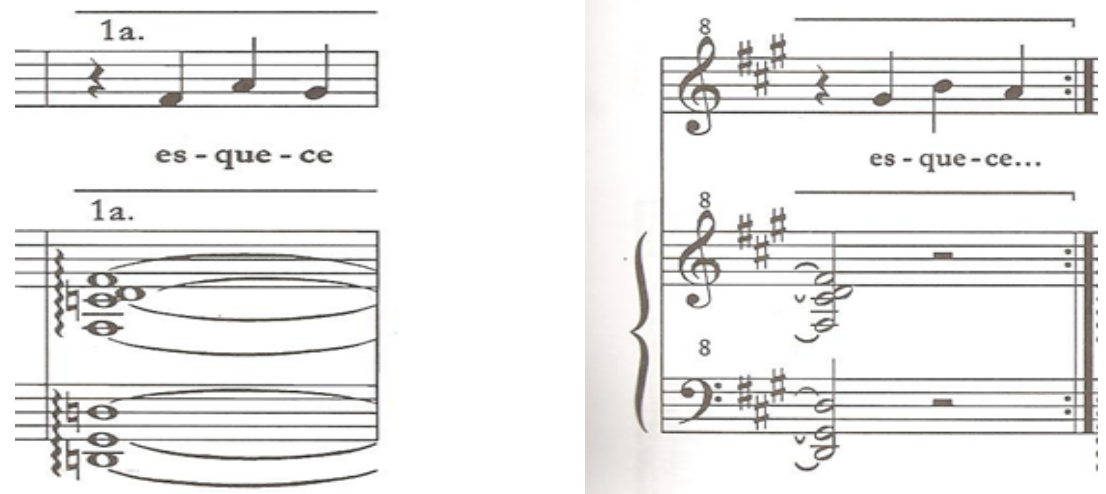


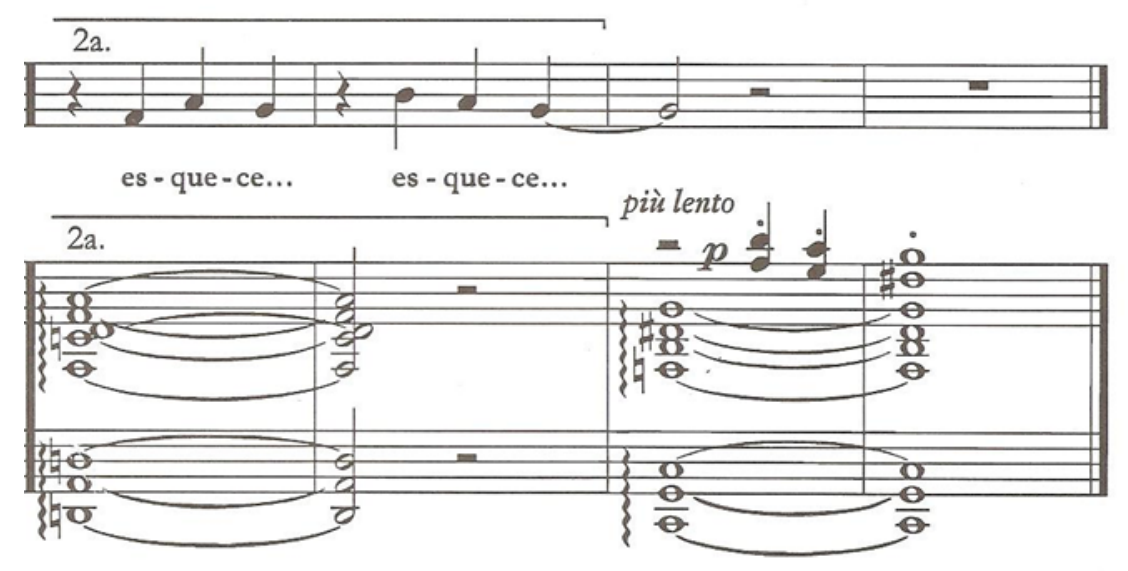

Partitura 3: "Voz da noite"

Fonte: Henrique de Curitiba (2003) - Seis Poemas de Helena Kolody: canções para soprano e piano.

A partitura propõe dois finais ao poema já que nela se expressa uma repetição após o primeiro final. Essa repetição leva à retomada da letra do poema desde seu início até a interrupção, feita no quinto verso: "diz baixinho", e, então, passa-se ao segundo final. Esse apresenta uma leve variação melódica e uma prolongação na última sílaba da canção, como se constata na partitura, mas que continua obedecendo aos aspectos próprios da fala propostos na poesia.

Verificamos, assim, o cuidado que teve Henrique de Curitiba (2003) na composição musical-poética dos elementos fônicos que aparecem na construção dos poemas de Helena Kolody. Tal fato, como foi apresentado, corrobora-se nos destaques realizados na musicalização às sílabas de maior intensidade fônica utilizadas na composição lírica. Aspecto que dá a tais signos maior importância na massa sonora e no sentido poético que, na linguagem musical, revela-se mediante a utilização de notas musicais mais agudas.

Conforme expõe Tatit (2003, p. 45),

[...] os motivos marcados pela periodicidade de seus acentos, jamais deixaram de apontar uma orientação qualquer no domínio das alturas, ainda que não lhe seja atribuída muita importância no contexto geral. O canto é essa eterna oscilação entre os ataques e os contornos valorizando ora a conjunção imediata entre os motivos, ora a conjunção à distância, mediada por uma rota a ser percorrida.

Essa "rota", pelo já exposto, parece que foi sensivelmente percebida na leitura que o músico erudito faz da poesia escrita pela poeta paranaense.

$\mathrm{Na}$ próxima composição eleita para exemplificar a relação entre as artes, o poema "Âmago", o músico curitibano propõe, novamente, uma similitude na direção das melodias entre as obras. Transcrevemos, abaixo, primeiramente o poema de Helena Kolody (2011, p. 54):

\author{
Âmago \\ Quem bebe da fonte \\ que jorra da encosta, \\ não sabe do rio \\ que a montanha guarda.
}


O poema "Âmago" está composto por versos de cinco sílabas, redondilha menor, fato que revela o cuidado da autora no momento de relacionar o conteúdo com a forma. Essa escolha pode ser explicada da seguinte maneira: o eu lírico apresenta, em tom de um adágio, uma recomendação ou conselho que visa a um despertar para as melhores coisas que podem ser encontradas se sairmos de nossa zona de conforto.

Esse caráter de aforismo que expressa o poema tem extrema relação com a sua forma, pois a preferência pela composição poética popular em língua portuguesa busca transmitir uma mensagem profunda sem a grandiloquência de outros esquemas métricos mais eruditos. Portanto, o poema é de aparente simplicidade métrica, mas com uma carga semântica complexa e emotiva que eleva sua mensagem ao plano do filosófico. É destacável, também, que o quarteto utilizado pela autora é constituído de uma única frase, cuja enunciação está repartida nos quatro versos, que contém somente dois sinais de pontuação: o primeiro, colocado no final do segundo verso, uma vírgula, e o último, com o ponto final.

Ao aplicarmos a visualização esquemática de extensão melódica utilizada anteriormente, o artista curitibano propõe, novamente, uma similitude entre a direção das melodias da obra poética e da obra musical, assim como verificamos no poema "Voz da noite".

Vemos que os dois primeiros versos do poema "Âmago" encontram-se estruturados da seguinte maneira:

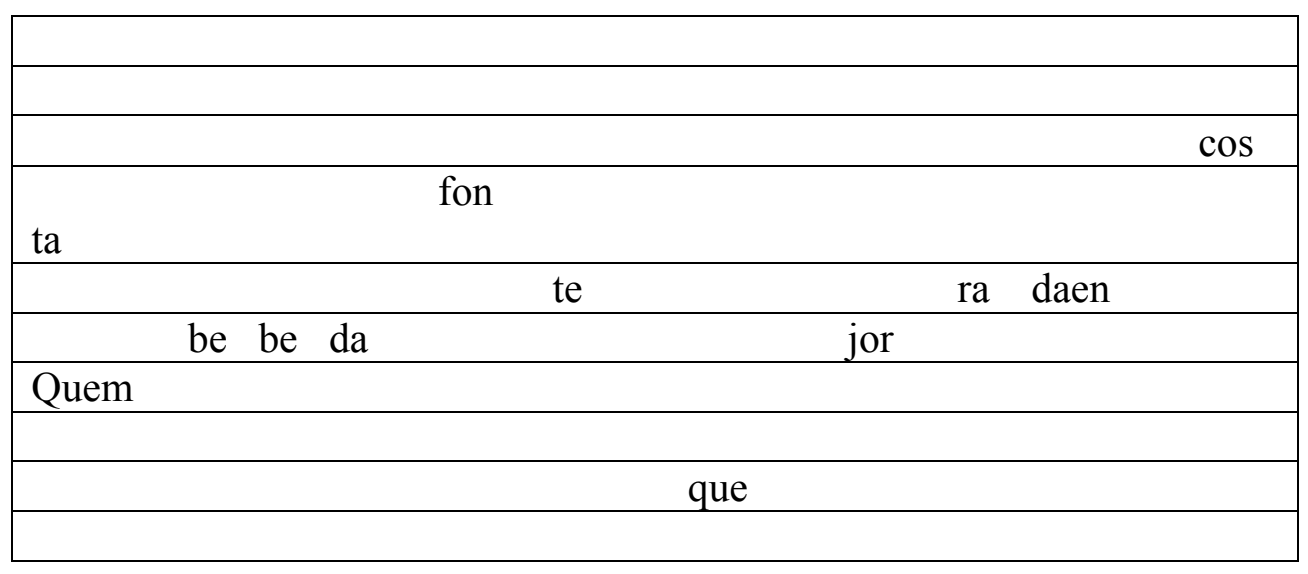

Esquema de extensão melódica - Fonte: Autor, baseado no esquema de Tatit (2007).

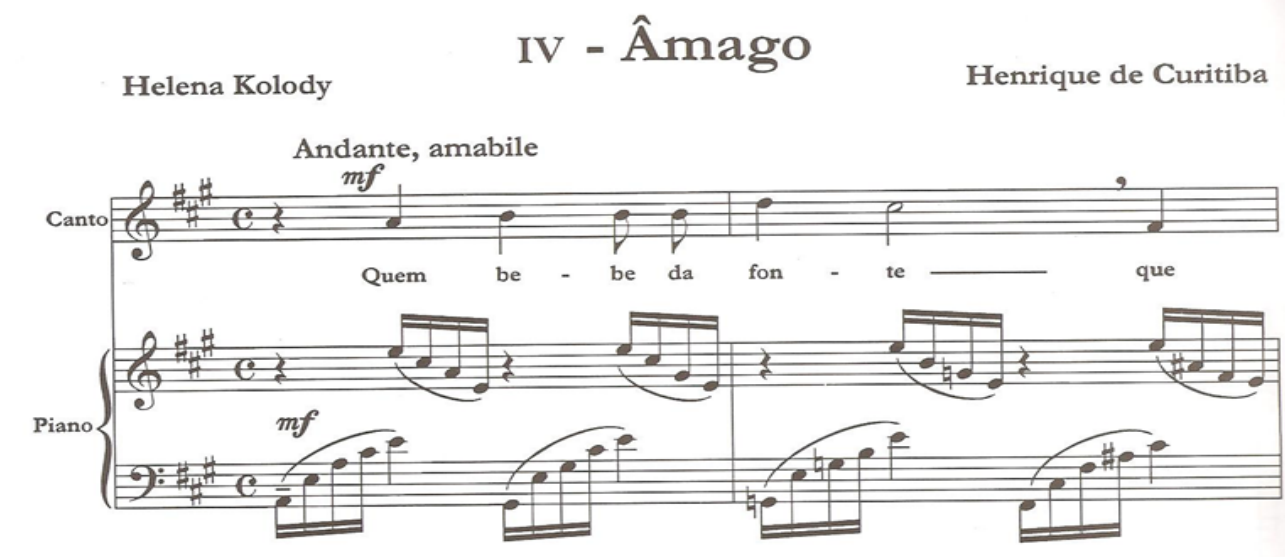




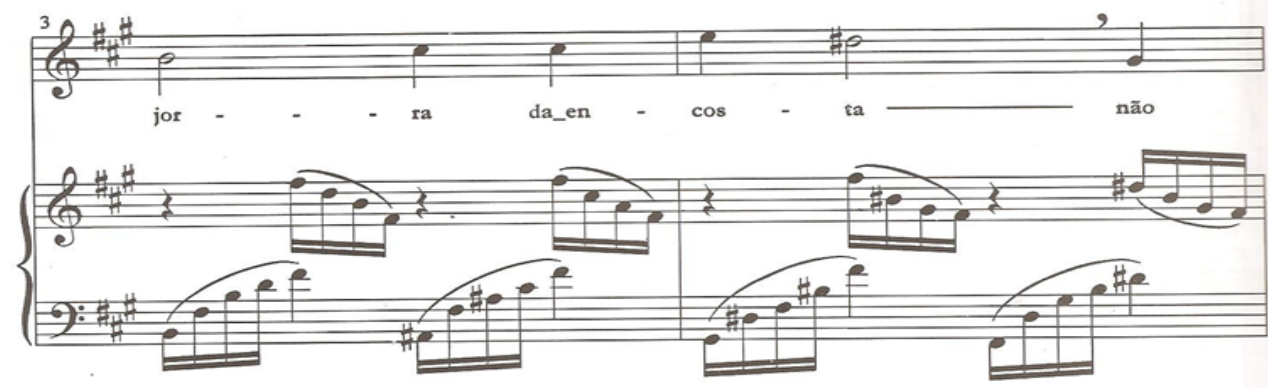

Partitura 4: "Âmago"

Fonte: Henrique de Curitiba (2003) - Seis Poemas de Helena Kolody: canções para soprano e piano.

Na proposta do esquema de extensão melódica, constatamos que o compositor destaca, com as notas mais agudas do enunciado, aquelas que o poema apresenta como sílabas tônicas: "Quem bebe da fonte/ que jorra da encosta,". Além desse destaque das sílabas acentuadas do verso, na partitura é omitido o signo de pontuação depois do segundo verso e substituído por uma cesura no canto que atua como vírgula. É importante considerar estas possibilidades de escrita que o poema ganha quando é utilizado para a criação musical ao ser transformado em um novo objeto artístico. Tal fato confirma a frutífera relação que nasce da convergência interartística utilizando novas formas de leitura e escrita da obra poética.

Continuando com a esquematização dos versos finais da obra de Kolody, transformada em canção, consideramos pertinente mencionar que a melodia segue uma linha que busca estar em consonância com o sentido da frase. Observamos que esses versos revelam a seguinte estrutura melódica:

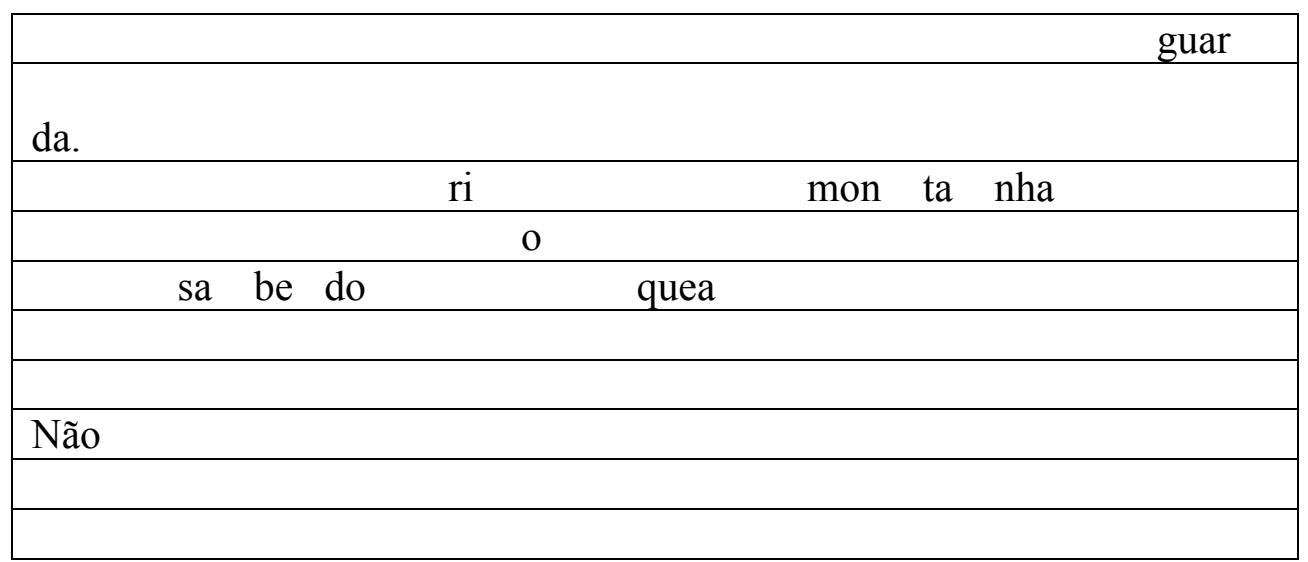

Esquema de extensão melódica - Fonte: Autor, baseado no esquema de Tatit (2007).

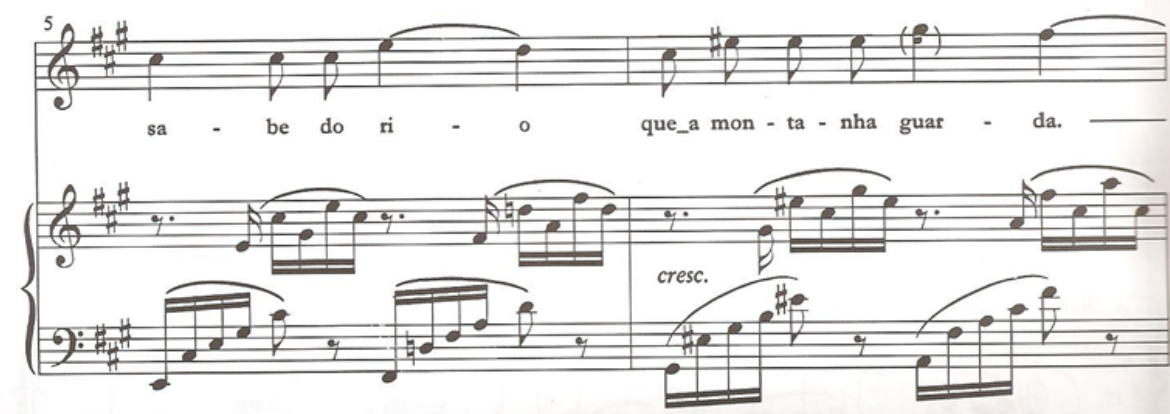




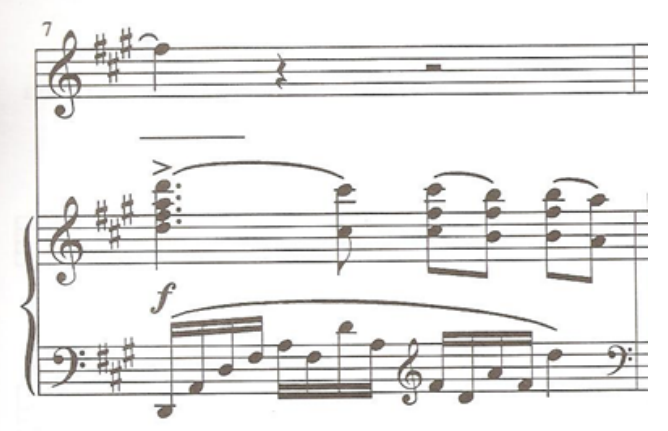

Partitura 4: "Âmago"

Fonte: Henrique de Curitiba (2003) - Seis Poemas de Helena Kolody: canções para soprano e piano.

$\mathrm{Na}$ parte correspondente aos versos três e quatro, a melodia continua seguindo o esquema da direção utilizada anteriormente. Essa destaca, com as notas mais agudas da partitura, as sílabas que contêm a acentuação nos versos do poema. Esse esquema, além de continuar em direção ascendente, apresenta, na partitura, a indicação de um crescendo, que desemboca no ápice da melodia, quando essa chega à nota "sol" na sílaba "guar", e repousa na sílaba "da", com a nota "fá", que se estende até o próximo compasso.

Na obra de Henrique de Curitiba (2003), apresenta-se um final que repete parte do poema. Na partitura, a canção estabelece, para o final da composição, uma repetição dos versos primeiro, terceiro e quarto: "Quem bebe da fonte/ não sabe do rio/ que a montanha guarda." Essa condensação, feita na leitura de Henrique de Curitiba (2003), resume, ainda mais, o aforismo proposto no poema de Helena Kolody, como podemos ver na esquematização abaixo:

\begin{tabular}{|c|}
\hline \multicolumn{2}{|c|}{} \\
\hline \multicolumn{2}{|c|}{ Fon } \\
\hline Quem be da \\
\hline \multicolumn{2}{|c|}{} \\
\hline \\
\hline \\
\hline
\end{tabular}

Esquema de extensão melódica - Fonte: Autor, baseado no esquema de Tatit (2007).

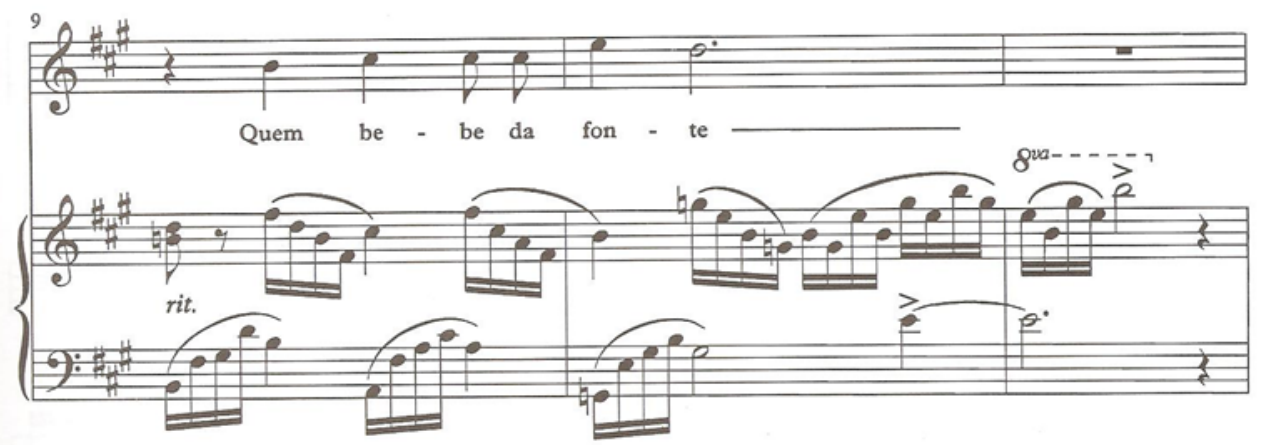

Partitura 4: "Âmago"

Fonte: Henrique de Curitiba (2003) - Seis Poemas de Helena Kolody: canções para soprano e piano. 
Volume 13 - Número 1 - mai/jul de 2018

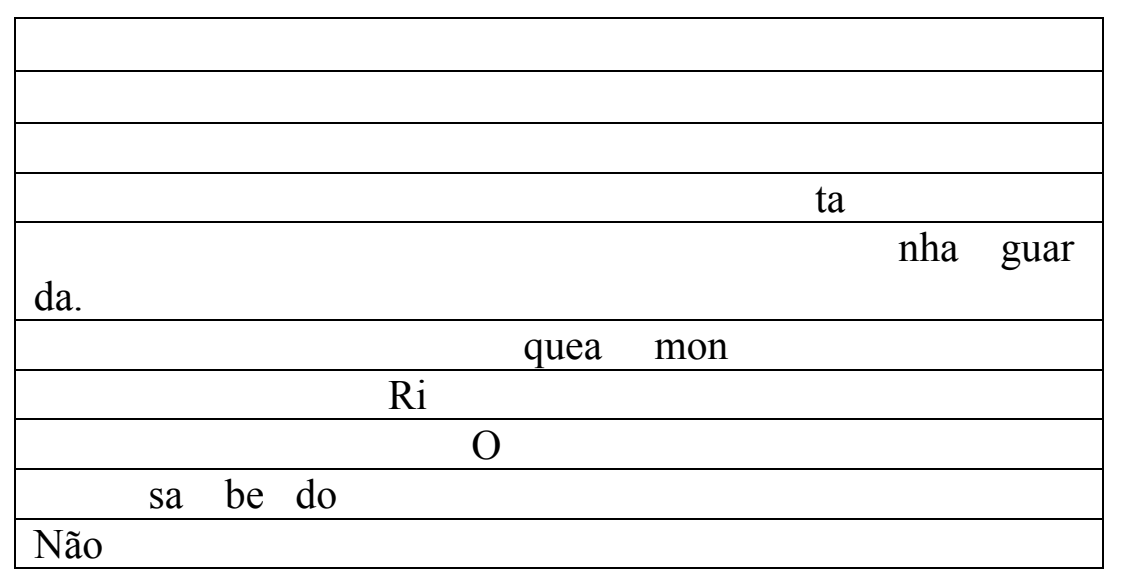

Esquema de extensão melódica - Fonte: Autor, baseado no esquema de Tatit (2007).

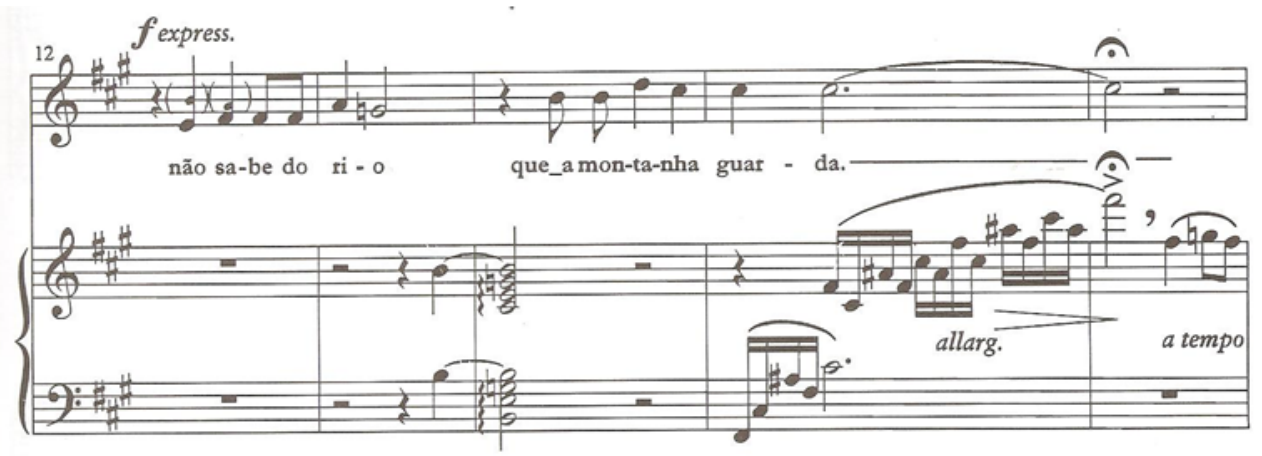

Partitura 4: "Âmago"

Fonte: Henrique de Curitiba (2003) - Seis Poemas de Helena Kolody: canções para soprano e piano.

$\mathrm{Na}$ repetição do primeiro verso, verificamos os mesmos recursos utilizados anteriormente: a presença da nota mais aguda para a sílaba acentuada. Na seção que pertenceria ao segundo verso, omitido nessa repetição da letra do poema para o final da musicalização, existe um compasso de silêncio. Esse atua, certamente, como remissão ao verso excluído: "que jorra da encosta", de certa maneira já presente na mente do leitorouvinte.

Já nos versos terceiro e quarto, temos a indicação, na partitura, de um forte expressivo, que emprega a formação esquemática utilizada até esse ponto da canção para o verso três, mas que se inverte no último verso, pois a nota aguda corresponde à sílaba "ta" e a obra termina com notas iguais para as últimas sílabas "nha - guar - da". Isso pode sugerir a imagem de que se alcançou, finalmente, a "subida", pela duração prolongada das notas, e que se chegou junto ao rio. Tal possibilidade interpretativa nos conduz, também, ao enunciado de que é "[...] impossível uma composição sem os ataques que sustentam os impulsos de sua continuidade ou sem a presença das durações vocálicas que, por menores que sejam, garantem sua direcionalidade no campo da tessitura. (TATIT, 2007, p. 45).

Desse modo, poema e música se completam na intencionalidade e na direcionalidade, embora resguardem suas próprias especificidades, segundo defende Souriau (1986), na obra La correspondencia de las artes, ao comentar que não haveria necessidade de romper o equilíbrio entre música e literatura ou mesmo subverter alguma, pois 
Volume 13 - Número 1 - mai/jul de 2018

colaboradora, [...] también se emancipa de las necesidades realmente descriptivas, para aportar a la obra común, lo que sólo ella puede darle: esa variedad, esa sinceridad, o sea flexibilidad del ritmo, esa magnificencia, esa fantasía, ese acento o esa ternura de las melodias, esa opulencia de armonías, en las cuales nunca la poesía, con los únicos recursos de los sonidos del lenguaje, podrá competir realmente con ella. (SOURIAU, 1986, p. 175-176).

Ao destacar as excelências da música na confluência das artes, o estudioso não deixa, contudo, de apontar, também, aqueles recursos específicos da linguagem poética que podem contribuir de forma singular para um grande enriquecimento do objeto artístico resultado de uma fusão de artes. Nesse sentido, o autor menciona:

Mientras que, por otra parte, la existencia de un enorme sistema de simbolizaciones
fonéticas, con el lenguaje, y la inmensa comodidad de recurrir a él, por una sintesis
tan fácilmente practicable cuando se trata de plantear la decoración, de presentar,
o de caracterizar los seres, o de explicar las ideas, siempre desalentará a la música
en el intento de rivalizar, en este terreno, con la literatura: Y en el de transportarse,
con toda su significación, y todas sus armas al segundo grado del arte. (SOURIAU,
1986, p. 176).

Portanto, a fusão resulta em um enriquecimento mútuo das especificidades que se potencializam na confluência música/poesia, conforme buscamos apresentar neste texto.

Os dois outros poemas de Kolody selecionados por Henrique de Curitiba para compor o conjunto o qual ele decidiu musicalizar, denominado "Seis Poemas de Helena Kolody: canções para soprano e piano", são: "Nunca e sempre" (KOLODY, 2011, p. 36) e "Viagem ao infinito" (KOLODY, 2011, p. 32), os quais transcrevemos na sequência:

\author{
Nunca e Sempre \\ Sempre cheguei tarde \\ Ou cedo demais. \\ Não vi a felicidade acontecer. \\ Nunca floresceram \\ Em minha primavera \\ As rosas que sonhei colher. \\ Mas sempre os passarinhos \\ Cantaram e fizeram ninhos \\ Pelos beirais \\ De meu viver.
}

Dos poemas selecionados pelo compositor curitibano para sua musicalização, a obra "Nunca e Sempre" é a composição kolodyana que mais irregularidade métrica apresenta dentro do grupo dos seis poemas. Composta por três estrofes que se dividem em dois tercetos e um quinteto, os versos estão construídos por uma metrificação irregular. Embora não exista o emprego de rima, à exceção dos versos sétimo e nono "Mas, sempre os passarinhos/ e fizeram ninhos", ou a regularidade do metro, a obra desenvolve um tratamento do tema com solvência e de maneira clara.

No primeiro terceto, o eu-lírico começa com uma exposição do tema da solidão, mediante o emprego de duas frases. O verso número um inicia com o emprego da palavra "sempre" presente no título e, no segundo terceto, inicia com "Nunca", invertendo a ordem proposta no título. No segundo terceto, expõe-se que aquilo que o eu lírico sonhou em algum momento não foi alcançado. 
Volume 13 - Número 1 - mai/jul de 2018

Vejamos, a seguir, o poema "Viagem Infinita", transcrito abaixo:

\section{Viagem infinita}

Estou sempre em viagem

O mundo é a paisagem

Que me atinge

De passagem.

Nesse poema a poeta volta à temática da efemeridade do tempo, tópico recorrente na composição de Helena Kolody. A composição está realizada por um verso isolado e um terceto. Os dois primeiros versos apresentam uma estrutura de cinco sílabas e os dois últimos de três sílabas poéticas, o que estabelece um equilíbrio na composição.

No começo do poema o eu-lírico expõe o tema anunciado no título. A poeta utilizou o recurso das consoantes fricativas "s", "v" e "g" e as consoantes nasais "m" e " $\mathrm{n}$ " que se tornam uma constante durante todo o poema "Estou sempre em viagem/ O mundo é a paisagem/ Que me atinge/ De passagem.", fato que auxilia na construção da passagem do tempo.

Outro ponto destacável é que o tempo verbal utilizado é o presente do indicativo que aciona a imagem do momento atual que o eu-lírico valoriza e se converte em efêmero.

\section{Considerações finais}

$\mathrm{Na}$ obra de Henrique de Curitiba (2003), podemos observar que, na eleição dos poemas, não necessariamente se levou em conta, no seu conteúdo poético, as referências explícitas à música ou a seu campo semântico. De maneira inversa, e paradoxalmente similar à Kolody, Henrique cria música para esses poemas, cujos conteúdos poéticos se veem plasmados nas melodias e harmonias que cada uma das composições musicais recebeu no processo de confluência de artes.

Referimo-nos ao fato de que esse processo de criação se deu de maneira inversa àquele que fez Helena Kolody, mas, por sua vez, similar a ele. Isto porque consideramos que, assim como a poeta pode "escutar" a música em seus poemas e, posteriormente plasmá-los em signos linguísticos, Henrique "escutou” a música nos signos linguísticos eleitos por Helena Kolody e, assim, pode imaginar como soariam na linguagem particular da qual se vale a música.

O diálogo que se produziu entre os dois artistas, cada um valendo-se da sua linguagem própria, possibilita-nos disfrutar da confluência das artes num único objeto: poesia/música.

No que diz respeito à composição musical, podemos expor que é um campo muito discutido, devido a que não existe um consenso unificado sobre o ato de compor por parte dos músicos. No entanto, uma das visões oferecidas pelo teórico Zamacois (1997) nos expõe, entre outras possíveis origens para a composição, que a influência do contexto é fundamental no processo criativo. Segundo o estudioso:

El temperamento y la sensibilidad influyen grandemente en la labor creativa del compositor. Entre éstos los hay de estilo grandilocuente y de expresión austera, tímida; de vuelo largo y de vuelo corto; que precisan de excitantes extramusicales para que su imaginación rinda, y que tan sólo en el regazo de la música pura saben expresarse [...]. (ZAMACOIS, 1997, p. 19). 
Neste sentido, conforme expressa Jaume Ayats (2015, p. 17), no prólogo que escreve à obra ¿Hay música en el hombre? (2015), de Blacking, "los valores sociales que asume una música y el efecto que produce dependen sobre todo del 'contexto': por esta razón el motivo que hace posible una actividad musical es siempre 'extramusical'." Todo ato de composição, seja poético ou musical, parece ser influenciado pelo contexto que circunda o artista, pois, de uma ou outra forma, resquícios desse confluir acabam sendo perceptíveis no resultado alcançado - como vimos nos poemas de cunho social de Kolody e, também, nos que a base está assentada na musicalidade.

Assim, em relação à composição musical, expomos o pensamento do músico e escritor Aaron Copland (2008), presente na obra Cómo escuchar la música, na qual ele comenta, desde sua experiência direta como músico, um aspecto que devemos considerar quando se busca entender o compositor e sua obra. Esse "no tiene que narrarnos una historia, como el novelista [...] ¿Qué es, pues, lo que nos da? Una sola respuesta me parece posible: se nos da a sí mismo. La obra de todo artista es, por supuesto, una expresión de sí mismo, pero ninguna tan directa como la del músico creador. (COPLAND, 2008, p. 238). Dessa forma, fica explícita a relação do compositor com a sociedade para a qual sua obra é dirigida: uma estreita relação pessoal, plena de subjetividade que, uma vez apoiada na própria poesia, ganha a força das metáforas e da linguagem artística em sua intenção comunicativa. Fato que uniu, de forma harmoniosa, o fazer poético de Helena Kolody e o fazer musical de Henrique de Curitiba.

Deste modo cabe mencionar que

[...] la composición musical se verá afectada por la vinculación entre el estilo musical, la cultura del momento y la ideología. Para establecer un mejor entendimiento de la música deberemos, pues, fijarnos en los aspectos dinámicos de la cultura, ya que va a ser en la cultura donde encontraremos aspectos extramusicales que son imprescindibles para comprender el universo sonoro. La cultura es la que dota de una función específica al sonido, la que establece los lugares para la interpretación de la música, la que convierte una canción en un símbolo, la que marca actitudes y valores. (HORMIGOS RUIZ, 2008, p. 149).

Isso, outra vez, une os dois artistas - poeta e músico - que buscam no simples o sublime e fazem da arte uma expressão possível de ser compreendida, apreciada e disfrutada pela grande maioria da gente. A produção poética de Helena Kolody, na confluência da lírica com a música que possibilita a ampliação do universo ouvinte-leitor, encontra-se em consonância com sua época e com o labor artístico latino-americano em busca de suas múltiplas e híbridas raízes identitárias. Tal ponto une, de forma singular e estreita, o fazer poético e a reflexão crítica e musical de ambos os artistas, cuja produção multifacetada está aqui contemplada.

\section{REFERÊNCIAS}

BLACKING, J. ¿Hay música en el hombre?. Madrid: Alianza, 2015.

COPLAND, A. Cómo escuchar la música?. México: Fondo de Cultura Económica, 2008.

CRUZ, A. D. Helena Kolody: a poesia da inquietação. Cascavel: Edunioeste, 2010.

CURITIBA, H. de. Seis poemas de Helena Kolody: Canções para soprano e piano. Curitiba: Ed. UFPR, 2003. 
HORMIGOS RUIZ, J. Música y Sociedad-Análisis sociológico de la cultura musical de la posmodernidad. Madrid: Fundación Autor, 2008.

KOLODY, H. Infinita Sinfonia. A. M. WOELLNER (Org.) Curitiba, PR: Edição do autor, 2011.

SLAMA-CAZACU, T. Lenguaje y contexto. Barcelona: Ediciones Griljaldo, 1970.

SOURIAU, E. La correspondencia de las artes. México: Fondo de Cultura Económica, 1986.

TATIT, L. Semiótica da canção. São Paulo: Editora Escuta, 2007.

ZAMACOIS, J. Temas de estética y de historia de la música. España: SpanPress, 1997. 